\title{
Quality Decline Analysis and Countermeasures of Undergraduate Thesis
}

\author{
Wan Diqing \\ School of Materials Science and Engineering \\ East China Jiaotong University \\ Nanchang, China \\ divadwan@163.com
}

\author{
Zhi Zhumin \\ School of Materials Science and Engineering \\ East China Jiaotong University \\ Nanchang, China
}

\begin{abstract}
Graduation thesis plays an irreplaceable role in the cultivation of undergraduates. It can cultivate college students' practical ability, innovation ability and entrepreneurial spirit, which is an important link in improving undergraduate teaching level. Based on the modern educational thought, the theory of higher education and psychology, in view of the current decline in the quality of undergraduate thesis, this paper provides some references for improving the quality of undergraduate thesis by changing the way of work, learning and assessment of teachers and students.
\end{abstract}

Keywords-undergraduate course; graduation thesis; quality assurance

\section{INTRODUCTION}

Graduation thesis is a comprehensive teaching link before graduation, in which students can comprehensively apply and deepen their understanding of theoretical knowledge, improve their ability to analyze and solve problems, and cultivate students' creative consciousness and innovation ability, perfectly fit the time concept of "Volkswagen entrepreneurial, Peoples innovation"[1-3]. In fact, the completion of graduation thesis is a very practical activity, from the topic selection to the research and collection of materials, from writing to the completion of the thesis, students need to hard work; But it has to admit that the current graduation thesis quality is declining[4-5]. Based on the modern educational thought, management theory, higher education theory and psychology, several problems existing in the work of undergraduates' graduation thesis are in-depth analysis with a unique perspective, and this paper proposed to change the students and teachers of learning, work, and assessment methods as the starting point for the future to improve the quality of graduation thesis.

\section{Several Important Problems Existing In the CURrent WORK OF UNDERGRADUATE THESIS}

\section{A. At the beginning of poor understanding of undergraduate thesis}

Graduation thesis is the final stage of undergraduate learning activities, but this activity is quite different as before, because in front of the undergraduate years learning activities are largely dominated by the teachers in class, students can seldom contact with practical engineering subject; moreover, it does not need to play undergraduates' subjective initiative in the analysis of problems and solve problems. It is very difficult to write a good paper if the student does not know enough about the whole thesis process at the beginning. In fact, nowadays a part of the undergraduates do not attach importance to graduation thesis has become a phenomenon. Survey shows that $50 \%$ of students do not know much about the process of graduation thesis and even $14.3 \%$ of the students don't understand the process of graduation thesis[6-7]. Therefore, in order to ensure and further improve the quality of graduation thesis, it is necessary to strengthen the publicity of the students' understanding of graduation thesis, so that students can clear the graduation thesis process before enter the graduation thesis and complete the graduation thesis schedule in advance.

\section{B. The time for students to work for undergraduate thesis is not enough}

Education plan set students must complete their thesis within $4 \sim 6$ months and some universities are even down to 2 $\sim 3$ months to complete it, but the actual times for writing a paper is about 1 month; Plus graduation thesis are mostly arranged in the last semester, at which the students are busy looking for a job or graduate reexamination, the comprehensive things causes students to complete the process of graduation thesis is very hasty. A serious shortage of time of graduation thesis writing, which can reflect the students do not explain the experimental phenomenon deeply in their paper, the analysis of experimental data is too simple, like an experimental report; In order to complete the graduation thesis, some students even directly copy paper or purchase from the online, Therefore, it can be seen that the actual completion time of graduation thesis brings about serious consequences [8-9].

\section{Formalism of graduation defense still exists}

After the completion of the thesis, graduation defense is arranged in order to check whether the students achieve the basic requirements and objectives of graduation thesis and to measure the quality of graduation thesis. Despite the management of thesis defense has been strengthened, but the formalism problem still exists. It is mainly manifested in the following aspects: one is formalism of the graduation thesis reviews, many students' graduation thesis only requires a teacher in the department to complete the review in a short period of time, however, as we know, the reviewing results in a 
short time is unscientific; secondary, during the defense, the reply time for a student is too short, because schools now require several classes in a department to finish the thesis work in a day or two, thus the teacher could not fully ask the questions; Third, students are not fully prepared. During the oral defense, some students often answered a few words can not go down the answer when they just encountered ask the relevant questions. The results of formalism of graduation defense still exists is that the elimination rate is too low; the majority of defense does not need to modify and approved by a formal [10-12].

\section{SOME KeYs TO IMPROVE THE QUALITY OF GRADUATION} THESIS

\section{A. Paying attention to relationship of Instructor and students' quality of graduation thesis}

Instructor is critical to improve the quality of graduation thesis. Often a good instructor can guide the outstanding graduation thesis, so what is the role of teachers in the process of complete undergraduate thesis? On the one hand, the instructor should be an expert in the field of topic selection and is very familiar with the subject of undergraduates, can give many constructive suggestions, which can guide the students to study in a short time; On the other hand, the research field provided by instructors can ensure the successful completion of the experiment because a good guide teacher usually is a master or doctoral tutor, in which team the research has certain experimental site, students have sufficient experimental conditions to complete the work of undergraduate thesis. In addition, good instructors have a strong sense of responsibility, will carefully selected topic, give students refers to clear the research emphasis and difficulties, and the answer to the student. In a word, a good instructor for the high quality completion of undergraduate thesis is an important guarantee. In addition, it necessary to be pointed out that the number of students in guidance should be scientific and reasonable, a lot of excellent instructors have heavy teaching scientific research task, thus it's difficult to guarantee it's a good proportion of the graduation thesis guidance of them are allowed to guide a dozen or even dozens of students.

\section{B. Introduce elimination system appropriately}

It is undeniable that the quality of the some thesis is so poor, but the final consideration of various factors, or let the student graduated, in other words whether the paper quality is good or bad does not affect the students graduation, so the attitude towards graduation thesis will mislead our students to a certain extent, which is actually the potential factor leading to the decline of the quality of graduation thesis. For this, we must carry on the warning work of the graduation thesis, properly to introduce elimination mechanism, so as to ensure the quality of degree conferred. How to introduce elimination mechanism? By what standard? Different school may have different standards, but no matter what kind of standard, if you want to strictly enforce knockout, it will enhance undergraduates' training quality is an effective means of control.

\section{Strengthen the early academic training}

The completing process of undergraduate thesis is actually an academic exercise. The influence of the early stage of the project or academic training on the quality of the final paper should be paid more attention. Nowadays, the majority of college students are lack of the ability to carry out scientific research independently and practical training opportunities hence it is difficult to put a creative idea and put idea to research practice. In the current environment of "Volkswagen entrepreneurial, Peoples innovation", students should be encouraged to participate actively as soon as possible to the research subject and scientific research work of instructor, it is necessary to encourage students who have a certain basis to actively participate in national or provincial research, encourage students to participate in certain competitions, especially senior students. Therefore, it is possible to strengthen the academic foundation of the students through the research and training programs, and to link up with the post graduation thesis. For the difficult and innovative scientific research training projects, it may even be considered to replace the graduation thesis.

In the contemporary undergraduate education in our country, most of the undergraduates during school can only deal with some basic knowledge, seldom come into contact with the professional research of frontier technologies. Most professional frontier technology research is performed by elite education graduate student, which leads to a group of outstanding undergraduate students can't get the opportunity to exercise. General colleges and universities in the project is mainly composed of two: the transverse and longitudinal projects. Longitudinal project generally refers to the state support with basic research program of science and technology; Transverse project usually is the enterprise and teachers together to complete the project, which is of great practical significance. So both transverse and longitudinal projects have reflected the forefront of professional science and technology. Undergraduate students to join these projects to unprecedented significance. Undergraduate students cultivate the students' interest in scientific research through these research projects of exercise. In addition, graduate students and mentors are often detained by the inherent professional thinking, can not use jumping thinking to think about the problem, while undergraduates in some ways to avoid such things happen. Under the guidance of this guiding ideology, in East China Jiaotong University a number of studios are set up by teachers, in which the main members of these studios are composed of undergraduates, graduates students. However, the undergraduates could deepen the understanding of the profession in these projects.

\section{Explore relationship between free topic selection and the quality of thesis}

Most of the topic selection of current students are designed by teacher, thus the students are lack of subjective initiative, so it is necessary to explore the role of students free topic selection. A good choice can guide the student to make the best of the ideal of scientific research if the student's interest is as a starting point. Actually, the topic can come in many aspects, one is from the literature reading, through reviewing articles on 
research do overall grasp, who can understand what is unresolved issues, or in some ways to solve the bad problem, but now it is found that most undergraduates rarely read the subject of the literature, moreover, the teacher rarely arranged to read the relevant literature, so the topic of this approach is actually undesirable. In addition, many students will encounter some scientific problems in the process of usual study and life and have impulse to solve, it can be encouraged to proposed relevant research topics, which may be a good research topic, but there have a number of issues need to pay attention, such as the subject should be modest, the subject is too small or too simple is not meet the requirements of the undergraduate thesis If the subject is too big, it is difficult to complete in just a few months' time. All in all, this kind of practice is not only beneficial to give full play to do deep understanding, but also appropriate to control. On the other hand, the instructor develop their literature reading, learning and research programs through a comprehensive could in-depth understand the students' individual interests and guide students to participate in scientific research activities better, so that students use amateur time step by step to carry out scientific research under the guidance of instructors could be a good way. This requires that the student should be in contact with their instructor frequently, and ask the instructor to have a very detailed study plan.

\section{E. Strengthen the mid-term examination of graduation thesis}

Executing mid-term examination of graduation thesis in the mid-term semester, students are required to complete the intermediate inspection report, after review and signed by the instructor, and handed over to the college for review and archiving. At the same time, we can find out the reasons and timely improvements for the mid-term examination of the problems found. Intermediate inspection reports including the completed the research content, the achievements obtained, the next step work plan and research content and so on. For medium-term work, teachers need to check whether the planned schedule execution, whether research direction deviation, etc., conscientiously carry out guidance and signed detailed guidance, and criticize and urge on the students of slow progress, negative work. In the mid-term inspection report, the instructor shall indicate the evaluation of the work done since the completion of the thesis, the completion of the interim and suggestions for future work. Like to need to change the graduation thesis topic in the process of graduation thesis, need to be submitted adjustment application form before the midterm examination to explain in detail the reasons for the need to replace the subject, failed to change the subject before the midterm examination reasons, etc., Reported to the college leadership, and changed the subject after getting permission.

\section{F. Introduced incentives mechanism to improve the quality of thesis}

Research and development of this incentive mechanism is good for improving the quality of undergraduate thesis. Such as whether an exemption to recommend the excellent-papers winner for a graduate student chance in their school? Or considering to give certain material rewards. In addition, the school should guide the student to correct learning motivation, create conditions to stimulate interest in learning, to guide students to pursue academic goals, etc. Graduation thesis is basic for the student with professional education, professional ethics education, and cultivating team spirit. Therefore, how to improve the quality of graduation thesis can fully influence the students' ideological and moral character, professional level, working ability and comprehensive quality.

\section{CONCLUSION}

Undergraduate education is a process of overall system; each link of education has its importance and necessity. In the current environment, under the influence of negative quote such as students' employment and students' mentality generally impetuous negative, the inner motive power of students to do paper is missing, so in this situation, it needs to find a scientific method to solve the problem. Therefore, it is of great help to improve the overall quality of undergraduate teaching by strengthening the quality research of undergraduate thesis.

\section{ACKNOWLEDGMENT}

This work was financially supported by the National Natural Science Foundation of China (51361010),(51665012) and the scientific research fund of Jiangxi provincial education department(GJJ150536).

\section{REFERENCES}

[1] Lv Qiufeng, Li Xiangqi. Reform and practice to improve the quality of undergraduate course graduation thesis [J]. Journal of Chemical Industry in Guangzhou, vol.9 (10) : pp.241-24,2013. (In Chinese)

[2] Wang Ruizhuo. College students' scientific research training and analysis $[\mathrm{J}]$. Journal of Heilongjiang Science and Technology Information,vol.1 (20) : pp.181-200,2008. (In Chinese)

[3] Liu Guifen, Yan QinLi. Tutorial system, effective exploration of cultivating college students' scientific research innovation ability [J]. Journal of medical within Youjiangminzhu College, vol.11(6) : pp.10861088,2006. (In Chinese)

[4] Shen Tong. Doctoral education quality improvement the key point of control research in China [D]. Hangzhou: Zhejiang University, Master thesis, 2005. (In Chinese)

[5] Wei Jie, Wang Dongtian. Research of teaching reform of undergraduate course graduation thesis. Journal of Jiangsu insitute of education(natural sciences),vol.26(4), pp.67-69,2009. (In Chinese)

[6] Zhou Xinhui. About the tutorial system to improve the quality of material chemistry profession undergraduate course graduation thesis study [J]. Journal of Chemical Industry in Guangdong. vol.38 (221): pp.204-208,2011. (In Chinese)

[7] Yang Guoliang.According to the specialized subject undergraduate program to train and develop innovation ability raise exploration [J]. Journal of teaching and research. vol. 4(3) : pp.24-27,2011. (In Chinese)

[8] $\mathrm{Hu}$ Tao, Li Jianlong. Credit system under the condition of human movement science the necessity to implement tutor system research $[\mathrm{J}]$. Journal of Information Science and Technology (academic). vol.2 (26) : pp.18 - 19, 2007. (In Chinese)

[9] Chen Yongjun, Wang Guogao. Based on the quantitative evaluation of the experimental technical personnel management mode of exploration and practice $[\mathrm{J}]$. Journal of Experimental Technology and Management. vol.30 (9) : pp.2013-205,2013. (In Chinese)

[10] Bao Xuexiong. Liberal arts class undergraduate course graduation thesis guidance of DPT [J]. Journal of Guangxi Higher Education Research. vol. (2) : pp.76-78,2002. (In Chinese)

[11] Xu Zheng. The five-year normal education in history teaching should highlight the people-oriented spirit[J]. Journal of Yanbian Institute of Education., vol.26 (6) : pp. 45-47,2012. (In Chinese)

[12] He Xiangmei. To carry out undergraduate supervisory system of higher education $[\mathrm{J}]$. Journal of Anhui University of Science and Technology (social science edition), vol.5 (3): pp. 90-92,2003. (In Chinese) 